\title{
Methods for Accurate Resistance Measurement
}

\author{
Medishetty Akhil, Bhaskar H Venkataramaiah, Geethrani P
}

\begin{abstract}
Many devices have components that have very low ohmic properties. The resistances of these components should be measured to ensure their value doesn't change. An overview is presented on precision resistance measurement for values less

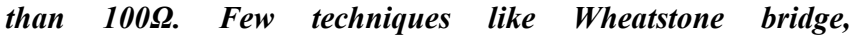
current-voltage method, current comparators are discussed here.

Keywords: Adaptive Wheatstone bridge, Direct current comparator, Resistance measurement
\end{abstract}

\section{INTRODUCTION}

The measurement of very large or very small quantities is always difficult, and resistance measurement is no exception. Values above $1 \mathrm{G} \Omega$ and values below $1 \Omega$ both present measurement problems. Resistance measurement is very important as it has various applications where some should have a very high resistance and some other should have very low resistance. Few of the applications are manufacturing components like resistors, inductors, chokes, manufacturing switches, relays, connectors, maintenance of power cables, automotive industries, fuse manufacturers. In all these applications, resistance measurement is done in order to maintain the resistance under pre-defined specifications[1].

\section{METHODS OF RESISTANCE MEASUREMENT}

The method used for resistance measurement depends on the value of the resistance. There are different methods for measuring low resistance and different methods for measuring high resistance. Wheatstone Bridge Ammeter-voltmeter method, voltage divider, Current comparators[1] are generally used to measure the low ohmic resistances. Current integrating tera ohmmeters, Adapted Wheatstone bridge are generally used to measure high ohmic resistances[4-7].

\section{BASIC METHODS OF LOW-OHMIC RESISTANCE MEASUREMENT}

Wheatstone bridge is a basic circuit which can be used for resistance measurement[2-3]. It contains a galvanometer in center whose reading depends on the values of resistors in the bridges. If the resistors are balanced, the reading on the galvanometer is null. Two of the four resistors are always fixed to a constant ratio. Out of the other two, one resistor is the DUT and the other is a standard resistor.

Revised Manuscript Received on May 15, 2020.

* Correspondence Author

Medishetty Akhil*, Department of Electronics and Communication Engineering, RV College of Engineering, Bengaluru-59

Bhaskar H Venkataramaiah, Senior Engineer, HD Renal V\&V, Baxter Innovations and Business Solutions Pvt. Ltd.

Dr. Geethrani P, Assistant Professor, Department of Electronics and Communication Engineering, RV College of Engineering, Bengaluru-59.

(C) The Authors. Published by Blue Eyes Intelligence Engineering and Sciences Publication (BEIESP). This is an open access article under the CC BY-NC-ND license (http://creativecommons.org/licenses/by-nc-nd/4.0/)
This resistor can be varied in such a way that the reading in the galvanometer is null. Based on the constant ratio and the standard resistance, the resistance of the DUT can be measured. A voltage divider is a circuit where a voltage which is a fraction of input voltage is created. In this circuit, the voltage is applied to one resistance and it is read across another resistance. If the values of the resistors are different with a large difference, The voltage generated will be almost equal to the input voltage. In this method, the resistance to which the voltage is applied is a standard resistance and the resistance across which the voltage is read is a variable resistance. As the resistance of the communication line in the board is very less when compared to the standard resistances, the output voltage will not differ much from the input voltage. Any resistance can be measured by sending a constant current through it and then measuring the voltage across it using measuring instruments. A constant current can be generated by using external current generator or can be designed by using transistors or OPAMPs. A simple transistor can be used as constant current source by providing a sufficient biasing voltage to it. The current generated will depend on the $V_{B E}$ potential. But the $\mathrm{V}_{\mathrm{BE}}$ potential s very unstable because it changes with respect to temperature. To compensate this effect OPAMP is used. This can be improved by connecting the $\mathrm{V}_{\mathrm{BE}}$ in the feedback loop of the OPAMP. By this arrangement, the OPAMP will compensate for the instability of the $\mathrm{V}_{\mathrm{BE}}$. When this method is employed for low ohmic resistance, the voltage values read will be very less and can vary easily due to the wires and other connections. To avoid this we might need to amplify the voltage read across the resistance. To achieve this, a differential amplifier can be used. This amplified value can be further easily read by any instrument or controller.

\section{DIRECT CURRENT COMPARATOR WITH CURRENT EXTENDER}

Direct Current Comparators are built to measure the resistance in the range of $1 \mathrm{ohm}$ to kilo of ohms. But they can even measure resistances less than $1 \mathrm{ohm}$ by improving the circuit. Generally a current extender as shown in Fig. 1 is used[1].

A current extender is a circuit where the current in the two branches is in ratio with respect to ration of the windings. These current converts a current of few 100mA to 100A.

The internal current source in the extender is adjusted to a current value by the internal current feedback system following the relation $\mathrm{N}_{\mathrm{s}} * \mathrm{I}_{\mathrm{s}}=\mathrm{N}_{\mathrm{x}} * \mathrm{I}_{\mathrm{x}}$, where $\mathrm{N}_{\mathrm{s}}$ and $\mathrm{N}_{\mathrm{x}}$ are the windings in the current extender and $\mathrm{I}_{\mathrm{s}}$ is the current flowing in the standard resistance and $\mathrm{I}_{\mathrm{x}}$ is current flowing in the DUT. The nanovoltmeter measures the deviation in the resistances ratio from the current ratio. $R_{x}$ is calculated by the eq. 1

Published By: 


\section{Methods for Accurate Resistance Measurement}

$$
R_{x}=\frac{R_{s}}{r}+\frac{V_{n u l l}}{r * I_{s}}
$$

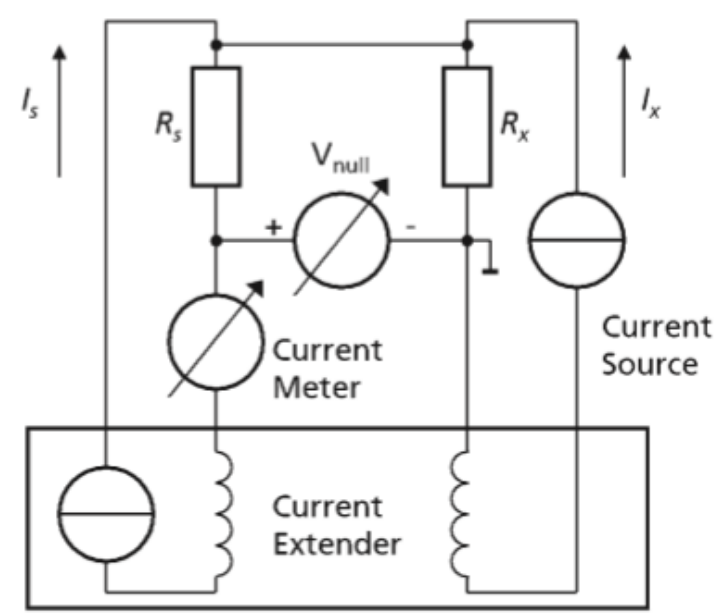

Fig 1. Schematic of Direct Current Comparator with

If the ratio of resistances is almost equal to the ratio of windings, then the reading in the nanovoltmeter will be almost zero. If the ratio of resistances and the ratio of windings vary a lot then the reading $\mathrm{V}_{\text {null }}$ in the nanovoltmeter will be huge and the accuracy of measurement will be very less. So the internal feedback system that adjusts the current source in the extender should be very accurate and the calibration of the nanovoltmeter should be very accurate. Accuracy of the system depends on the value of the chosen standard resistance.

\section{ADAPTED WHEATSTONE BRIDGE METHOD}

Wheatstone bridge is a commonly used method in measuring any value of resistance. A lot improvements were done on this Wheatstone bridge method to accurately measure high-ohmic resistance. One of those is to replace the resistances providing a constant ratio with adjustable voltages as shown in Fig. 2[5].

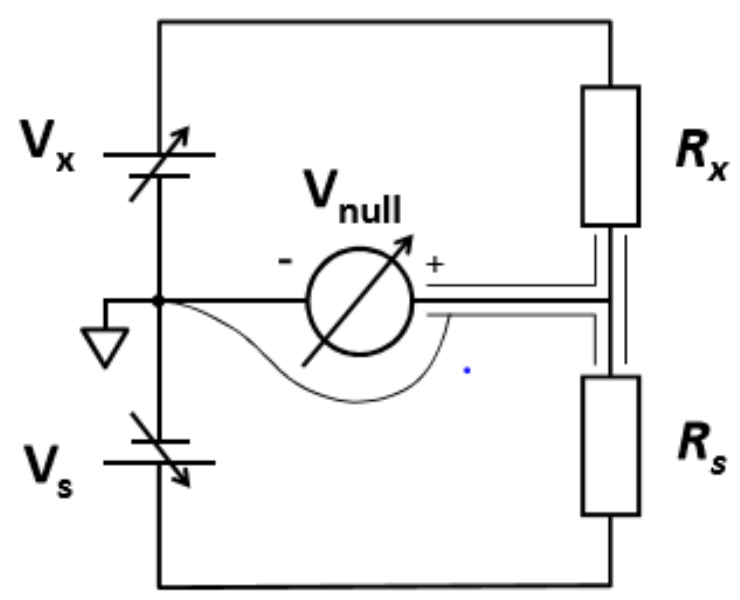

Fig 2. Schematic of Adapted Wheatstone bridge for High-Ohmic Resistances

A voltage $V_{x}$ is applied across the test resistance $R_{x}$ and a voltage $V_{s}$ is applied across a standard resistance $R_{s}$. Both the Current Extender

voltages are adjustable voltages. The ratio of the voltages and the reading of the voltmeter determines the value of the test resistance. Voltage $\mathrm{V}_{\mathrm{s}}$ is adjusted until the voltmeter reads zero voltage. If the voltmeter reading is zero, then the ratios $\left(-\mathrm{V}_{\mathrm{s}} / \mathrm{V}_{\mathrm{x}}\right)$ and $\left(\mathrm{R}_{\mathrm{s}} / \mathrm{R}_{\mathrm{x}}\right)$ are equal.

$$
R_{x}=-\frac{V_{x}}{V_{s}} * R_{s}
$$

As the applied voltages are adjustable and easily calibratable, there very less chances of uncertainty in the voltages and the accuracy will be high. The null detectors can be either nanovoltmeter or electrometer.

\section{POSSIBLE MEASUREMENT ERRORS}

Measurement errors are the errors which occur due to the equipment used or due to the environment. The most common sources of these errors are impure connectors, measurement noise, temperature effects, accuracy of the voltmeters. The connectors which are used for making the connections in the circuit should be clean and free from oxides which may insulate the path and may provide high resistances in the path of the current. Any current carrying conductor produce a small amount of magnetic field across it. This magnetic field may cause variations in the voltage levels of other lines leading to erroneous in the readings. The test resistance also contributes a lot for the error. When two conductors of different material are joined at a point, a small emf called Thermal emf is generated which makes a lot of differences in the low-ohmic resistance measurement. The resistivity of any conductor mainly depends on the temperature of the environment around it. If the temperature varies a lot, there will be fluctuations in the measurement of resistance. When measuring resistance all these scenarios should be taken care of for accurate measurement of the resistance.

\section{CONCLUSION}

Measurement techniques for measuring the resistance accurately have been discussed here along with the factors affecting the accuracy. All these techniques can be automated using controllers and reduce the manual effort and human errors. When it comes to the measurement of low ohmic resistances, the power factor comes into play. As the voltages in these circuits is very less, shielding and proper grounding connections should be taken care. Furthermore, leakage currents in the circuit should be taken care. In the case of high ohmic resistances, it takes long settling times which makes the automation little difficult. High ohmic resistances are difficult to manufacture and also measure. The adverse effects of temperature and humidity are inevitable hence require accurate temperature measurement and control.

\section{REFERENCES}

1. E. Houtzager and G. Rietveld, "Automated Low-Ohmic Resistance Measurements at the $\mu \Omega / \Omega$ Level," in IEEE Transactions on Instrumentation and Measurement, vol. 56, no. 2, pp. 406-409, April 2007.

2. X. Huang, X. Zhang, Y. Tong and J. Cai, "An AC Four-Terminal Low Value Resistance Bridge," 2018 Conference on Precision Electromagnetic Measurements (CPEM 2018), Paris, 2018, pp. 1-2.

\section{Published By:}

Blue Eyes Intelligence Engineering 
3. Satrapinski et al., "A low-frequency current comparator for precision resistance measurements," 29th Conference on Precision Electromagnetic Measurements (CPEM 2014), Rio de Janeiro, 2014, pp. 760-761.

4. F. Lin, C. Li, B. Liang and H. Shao, "Ultra-high resistance measurement based on non-contact electrostatic voltmeter," 2016 Conference on Precision Electromagnetic Measurements (CPEM 2016), Ottawa, ON, 2016, pp. 1-2.

5. G. Rietveld and J. van der Beek, "Active-arm resistance bridge with voltage null-detection for precision measurement of resistances above $1 \mathrm{M} \Omega$," 2012 Conference on Precision electromagnetic Measurements, Washington, DC, 2012, pp. 199-200.

6. G. Rietveld, D. Jarrett and B. Jeckelmann, "Accurate high-ohmic resistance measurement techniques up to $1 \mathrm{P} \Omega$," 29th Conference on Precision Electromagnetic Measurements (CPEM 2014), Rio de Janeiro, 2014, pp. 290-291.

7. Ö. Erkan, G. Gülmez, E. Turhan and C. Hayirli, "Active Guarded Wheatstone Bridge for High Resistance Measurements Up to $100 \mathrm{~T} \Omega$ at TÜBITAK UME," 2018 Conference on Precision Electromagnetic Measurements (CPEM 2018), Paris, 2018, pp. 1-2.

\section{AUTHORS PROFILE}

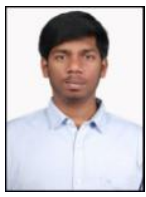

Medishetty Akhil is currently pursuing his Bachelor of Engineering Degree as a student of 8th Semester from Electronics and Communication Department, R.V. College of Engineering, Bengaluru. He is also working as an Intern V\&V Engineer with Baxter Innovations and Business Solutions Pvt. Ltd., Bengaluru since January 2020. He has worked on some of the projects on memory designs with considering the power dissipation as the main parameter.

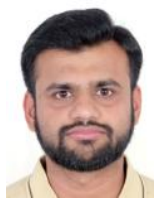

Bhaskar H. Venkataramaiah is working as a Senior Engineer, Verification and Validation in Baxter Innovations and Business Solutions Pvt.Ltd. He has got around 9 years of experience in hardware systems. He has obtained Bachelor of Engineering degree from PES College of Engineering. He has worked in various phases of systems engineering- system design and development, verification, product life cycle management etc. He has worked in multiple new product introductions (NPI) and holds a patent.

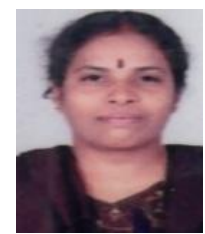

Dr. Geetharani P is working as Assistant Professor, Department of Electronics and Communication Engineering, RV college of Engineering, Bengaluru. She has got 21 years of teaching experience. She has obtained Bachelor of technology degree from BMS Engineering college, Bangalore in the year 1995 and obtained Master of Technology degree from R.V. College of Engineering, Bangalore in 2008. She completed her $\mathrm{PhD}$ degree in the year 2018 from Bangalore University, Bangalore, India. She has published 4 papers in National conferences and 4 papers in International journals. Her area of interests includes Optical Fiber Communication and Satellite Communication.

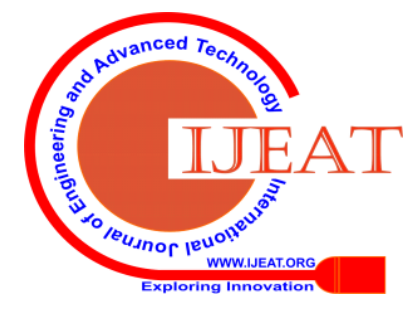

